\title{
CAPÍTULO 9 \\ CRESCIMENTO URBANO E OS IMPACTOS AMBIENTAIS CAUSADOS POR FROTA VEICULAR MUNICIPAL
}

\author{
Nathália Melo Giuliatti. E- mail: nathaliagiuliatti@ hotmail.com \\ Rafael Baia da Rocha; Airton Freire Cavalcanti Filho; Fabiane Frances Araújo \\ Gomes \\ 1;2 - Autora para correspondência \\ 2 - Universidade do Estado do Pará - Engenharia Ambietnal_2015_Campus VI - \\ Paragominas - PA. \\ DOI:10.4322/978-85-455202-0-7-09
}

\begin{abstract}
RESUMO
O crescimento urbano resulta, dentre outros fatores, no aumento da frota de veículos de um município, de modo que esse aumento geralmente gera impactos ambientais negativos ao meio ambiente e à população local. Esta pesquisa tem por objetivo relacionar o crescimento urbano e econômico de Paragominas-PA aos impactos ambientais causados pela frota veicular do município nos últimos 53 anos. Para tanto, foram analisados dados de população, produção agrícola e frota, além de qualificados alguns impactos ambientais causados no município desde a fundação, em 1965. O método utilizado nessa pesquisa foi o dedutivo, complementado com levantamento de dados bibliográficos e documentais com recorte temporal situado entre 2009 e 2018. A pesquisa apresenta abordagem quantiqualitativa, com natureza observativa e procedimento de revisão bibliográfica. $\mathrm{O}$ método de avaliação de impacto ambiental utilizado foi o Ad Hoc, devido à abordagem simples. Os dados obtidos indicaram que desde o crescimento da atividade econômica de extrativismo vegetal madeireira, os impactos causados pela frota municipal foram mais diversificados.
\end{abstract}

PALAVRAS-CHAVE: Ad Hoc; Atividade Econômica; Avaliação de Impacto Ambiental; Veículos

\begin{abstract}
Urban growth results, among other factors, in the increasing of the fleet of vehicles on a city, so that this increase usually generates negative environmental impacts to the environment and to the local population. Thus, this research aims to relate the urban and economic growth of Paragominas-PA to the environmental impacts caused by the municipal vehicle fleet in the last 53 years. For this purpose, data on population, agricultural production and fleet analyzed, as well as some environmental impacts caused
\end{abstract}


in the city since its founding in 1965 . The method used in this research was deductive, complemented with collection of bibliographical and documentary data within a period located between 2009 and 2018. The research, thus, is quantitative and qualitative, observative and has a bibliographic review procedure. The method of environmental impact assessment used was Ad Hoc, due to the simple approach. The data obtained indicated that since the growth of the economic activity of extractives logging, the impacts caused by the municipal fleet were more diverse.

KEY WORDS: Vehicles; Environmental Impact Assessment; Ad Hoc; Economic Activity.

\section{INTRODUÇÃO}

O município de Paragominas foi fundado em 1965, mas o povoamento do local teve início durante a segunda metade da década de 1950. Quando a colonização foi iniciada por uma frente pioneira, o governo brasileiro estava preocupado com a possibilidade de a Amazônia ser internacionalizada pelos norte-americanos, o que incentivou a ocupação do Norte com o lema "Integrar para não entregar" (BERGAMIN, 2015, OLIVEIRA; GOMES; CABRAL, 2012).

Desde a fundação até a década de 1970, a principal atividade econômica do município era a pecuária. No período entre 1980 e 2000, a atividade madeireira teve destaque, o que tornou o município um dos maiores polos madeireiros do Brasil. A partir de então, a crise no referido setor, devido à extração excessiva, foi responsável pelo crescimento de outras atividades, a agricultura para exportação e a mineração (MACHADO. LOBO; TOURINHO, 2015).

Todas essas atividades contribuíram para o crescimento da frota e do tráfego de veículos no município, uma vez que elas necessitam de meios de transporte para a escoamento da criação, extração e produção agrícola. Além disso, tais atividades influenciaram o crescimento populacional, principalmente devido à migração de pessoas advindas de outros municípios e estados, o que também contribuiu para o aumento da frota (COSTA et al., 2013).

Dessa forma, observa-se que o crescimento urbano e econômico está diretamente relacionado ao aumento da frota veicular, e esse aumento pode ocasionar impactos ao meio ambiente. Assim, esta pesquisa justifica-se, devido aos impactos causados pelo setor de transportes, no que tange ao tráfego de veículos, que está em constante em expansão. Nesse sentido, esta pesquisa tem por objetivo correlacionar o crescimento urbano e econômico de Paragominas-PA aos impactos ambientais causados pela frota veicular do município nos últimos 53 anos.

IMPACTO AMBIENTAL 
O conceito de impacto ambiental é definido, no Brasil, pelo Conselho Nacional de Meio Ambiente - CONAMA, resolução n, 001:1986, art. $1^{\circ}$ : qualquer alteração das propriedades físicas, químicas e biológicas do meio ambiente, causada pelo sistema produtivo humano, direta ou indiretamente, e que tem consequências sobre a saúde, a segurança e o bem-estar da população, bem como sobre o meio ambiente (BRASIL, 1986; PARIZOTTO et al., 2012).

\section{AVALIAÇÃO DE IMPACTO AMBIENTAL - AIA}

A Avaliação de Impacto Ambiental - AIA é um instrumento da Política Nacional do Meio Ambiente - PNMA, cuja aplicação está associada principalmente ao licenciamento. Nesse caso, ela é realizada previamente à instalação e operação de determinado projeto com potencial de causar impacto ambiental. O objetivo da AIA é fornecer suporte à análise das solicitações de licença ambiental e à tomada de decisão (ALMEIDA; MONTAÑO, 2015; MIRAGLIA; GOUVEIA, 2014).

A AIA é, portanto, uma ferramenta de caráter preventivo usada nas políticas de meio ambiente e gestão ambiental. Por isso, possui finalidade de assegurar que um determinado projeto, passível de causar danos ambientais, seja analisado conforme os prováveis impactos no meio ambiente, e que esses mesmos impactos sejam analisados e tomados em consideração no seu processo de aprovação (TURRA et al., 2017).

\section{LEGISLAÇÃO E NORMAS AMBIENTAIS NACIONAIS REFERENTES À FROTA VEICULAR}

A AIA, por ser avaliativa de impactos, deve ser aplicada a diversas atividades e setores que sejam potenciais causadores de impactos. Dessa forma, o setor de transportes é um dos que devem ser avaliados quanto a projetos e políticas, pois os veículos contribuem com a maior parte da poluição do ar nas cidades. Nos centros, o tráfego é responsável por $80 \%$ a $90 \%$ destes poluentes e esta situação é particularmente grave em cidades de países em desenvolvimento (BATTERMAN; CHAMBLISS; ISAKOV, 2014).

No Brasil, a legislação que dispõe sobre impactos ambientais ocasionados pela frota de veículos é escassa. Destacam-se leis e normas referentes apenas à regulamentação da emissão de poluentes por veículos automotores e a limites de ruídos (Quadro 1). 
Quadro 1 - Sete resoluções do Conama sobre a emissão de poluentes por veículos automotores no Brasil.

\begin{tabular}{|c|c|}
\hline $\begin{array}{l}\text { Resolução } \\
\text { CONAMA }\end{array}$ & Ementa \\
\hline n. $230: 1997$ & $\begin{array}{l}\text { Dispðe sobre a normatizaçðo dos aditivos, combustiveis ou procedimentos operacionais que } \\
\text { possam emitir poluentes atmosféricos com variaçð̄es acima do padråo. }\end{array}$ \\
\hline n.272:2000 & Dispð̄e sobre o limite máximo de decibéis permitido para cada categoria de veiculo automotor. \\
\hline n.03:2008 & $\begin{array}{l}\text { Referente aos limites máximos de emissto para motores do ciclo Diesel destinados a veiculos } \\
\text { automotores pesados novos, nacionais e importados. }\end{array}$ \\
\hline n.14:2009 & $\begin{array}{l}\text { Altera a Resoluçåo Conama } n^{\circ} 18 \text {, de } 06 \text { de maio de 1986, e reestrutura a Comissđ̃o de } \\
\text { Acompanlamento e Avaliação do PROCONVE - CAP, em seus objetivos, Competência, } \\
\text { composiçăo e funcionamento. }\end{array}$ \\
\hline n. $15: 2009$ & $\begin{array}{l}\text { Dispðe sobre a nova fase de exigências do Programa de Controle da Poluiçào do Ar por Veiculos } \\
\text { Automotores-PROCONVE para veiculos automotores leves novos de uso rodoviário. }\end{array}$ \\
\hline n.18:2009 & $\begin{array}{l}\text { Dispðe sobre critérios para a elaboração de Planos de Controle de Polujção Veicular - PCPV e } \\
\text { para a implantação de Programas de Inspeção e Manutenção de Veiculos em Uso - I/M pelos } \\
\text { orgãos estaduais e municipais de meio ambiente e determina novos limites de emissăo }\end{array}$ \\
\hline n.35:2011 & $\begin{array}{l}\text { Altera a redação do art. } 20 \text { e do art. } 33 \text { da Resolução no } 418 \text {, de } 25 \text { de novembro de } 2009 \text {, alterada } \\
\text { pela Resolução no } 426 \text {, de } 14 \text { de dezembro de } 2010 \text {, e regulamenta a entrada em vigor nos estados } \\
\text { e nos municípios dos programas de inspeção e manutenção dos motociclos e veiculos similares. }\end{array}$ \\
\hline
\end{tabular}

Fonte: autores (2018).

Além do crescimento da produção de veículos automotores no Brasil, a inexistência de políticas públicas referentes à retirada de modelos de veículos mais antigos do mercado também requer atenção do governo, pois estes, a partir de vinte anos de uso, tendem a poluir trinta e quatro vezes mais que um modelo novo (XIMENES et al., 2008).

\section{METODOLOGIA}

A pesquisa foi realizada no município de Paragominas, mesorregião sudeste do estado do Pará, com população estimada em 110.026 habitantes. O município possui extensão territorial de $19.342,254 \mathrm{~km}^{2}$ e apenas $5.1 \%$ das vias públicas urbanizadas, ou seja, com presença de bueiros, calçada, pavimentação e meio-fio (IBGE, 2010, 2016, 2017)

Figura 1 - Localização do município de Paragominas-PA.

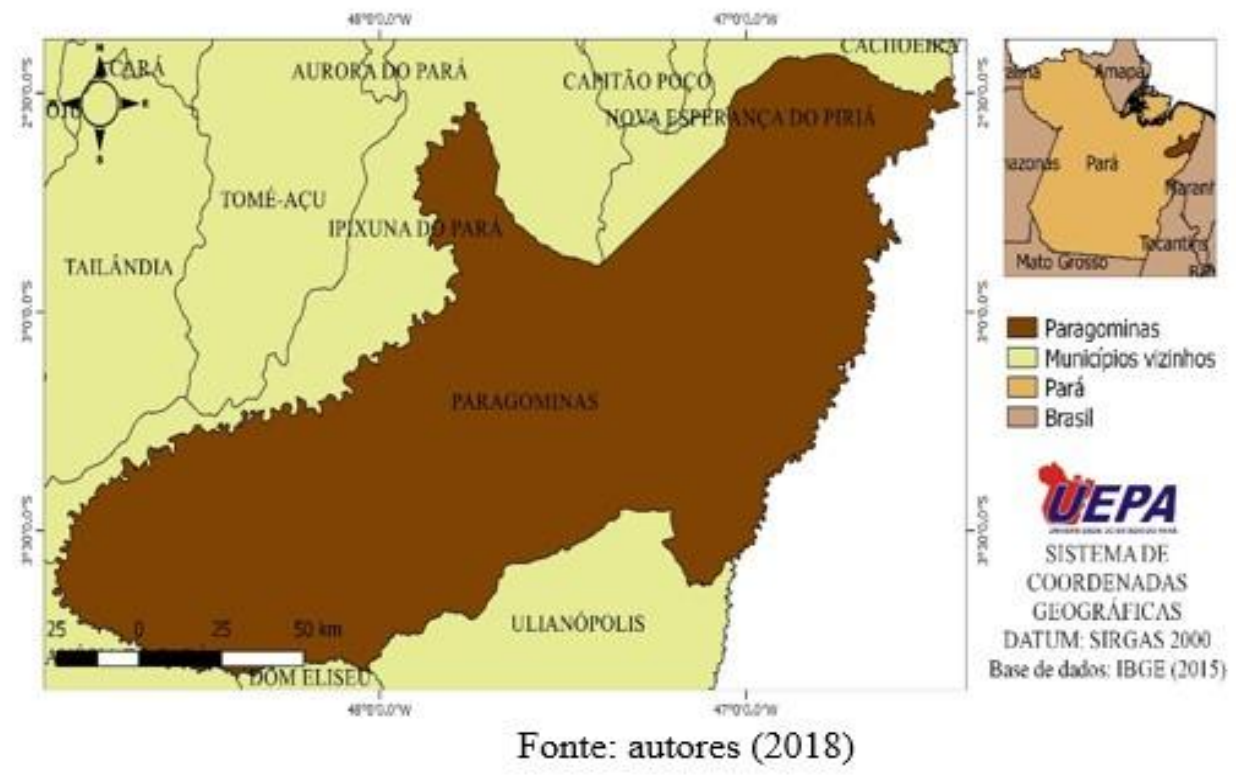


O clima local é do tipo quente e úmido, com temperatura anual média de $26^{\circ} \mathrm{C}$ e umidade relativa do ar de $81 \%$ (BASTOS et al., 2010). Quanto à hidrografia do município, ela é constituída pelas bacias hidrográficas do rio Gurupi e do rio Capim (PINTO et al., 2009). A rodovia BR-010 (Belém-Brasília) atravessa o município cerca de $12 \mathrm{~km}$ a leste da zona urbana.

O método utilizado nessa pesquisa foi o dedutivo (PRODANOV; FREITAS, 2013), pois o estudo parte das teorias e leis consideradas gerais e universais: legislação nacional e estudos anteriores. Além de explicar a ocorrência de fenômenos particulares como os impactos ambientais negativos causados pela frota de veículos de Paragominas Esse método foi complementado com levantamento de dados documentais com recorte temporal situado entre 2009 e 2018, cuja escolha prende-se ao fato de informações sobre o tema central dessa pesquisa, na última década e que foram publicadas.

As bases para esse levantamento foram: Science Eletronic Library Online SciELO; Coordenação de Pesquisa e Aperfeiçoamento do Ensino Superior - CAPES, periódicos, GOOGLE SCHOLAR e Instituto Brasileiro de Geografia e Estatística IBGE. Em relação à pesquisa, ela apresenta abordagem quantiqualitativa, com natureza observativa e procedimento de revisão bibliográfica (SAKAMOTO; SILVEIRA, 2014).

\section{MÉTODO DE AVALIAÇÃO DE IMPACTO AMBIENTAL}

O método de avaliação de impacto ambiental utilizado foi o Ad Hoc. Ele é baseado no conhecimento dos responsáveis técnicos pela avaliação e é adequado para casos quando há escassez de dados acerca do objeto de estudo, de modo que fornece orientação para avaliações posteriores. Os impactos são identificados geralmente por meio de brainstorming e podem ser organizados e apresentados em tabelas ou matrizes (OLIVEIRA; MOURA, 2009).

Nesse método, a avaliação aborda os impactos de forma simples e de fácil interpretação. Nesse sentido, não é feito exame detalhado das intervenções e das variáveis ambientais envolvidas, geralmente apenas as considera de forma bastante subjetiva e qualitativa. Assim, o método Ad Hoc pôde ser realizado em um curto espaço de tempo e possui custo mais baixo (CREMONEZ et al., 2014).

\section{SÉRIE TEMPORAL PARA O MUNICÍPIO EM ANÁLISE.}

A pesquisa refere-se à série temporal compreendida entre 1965 e 2017, com início no ano de fundação de Paragominas-PA. Para análise dos impactos ambientais causados pela frota veicular no referido período, a série foi dividida em três momentos: 1965-1979, 1980-1999 e 2000-2017 (Tabela 1), que estão associados aos três ciclos econômicos que ocorreram no município de Paragominas (MACHADO; LOBO; TOURINHO, 2015). 


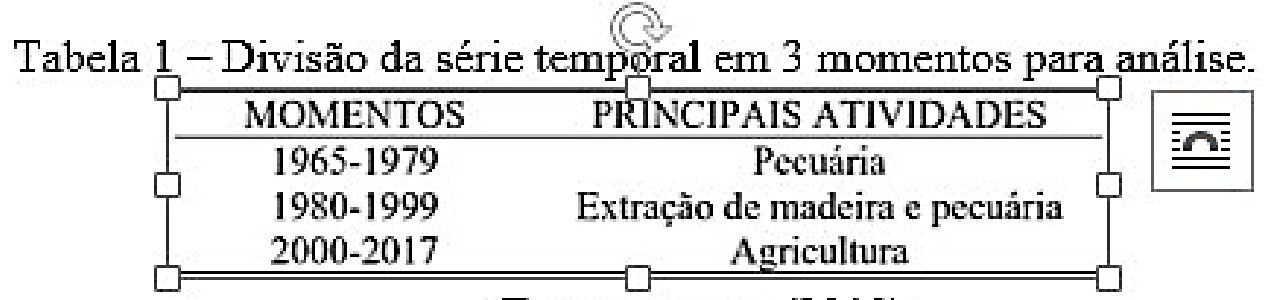

Fonte: autores (2018)

\section{TRATAMENTO ESTATÍSTICO DOS DADOS}

Os dados coletados referem-se a diferentes períodos, pois as séries temporais disponibilizadas no site do IBGE são limitadas. Os dados de população são apresentados para o intervalo de 2000-2017; os de produção agrícola para 1990 e 2016; e os de frota para 2005 a 2016. Dessa forma, foram aplicadas técnicas estatísticas (médias) para preenchimento das falhas contidas em algumas das séries temporais analisadas.

Para tanto, foi calculado inicialmente o coeficiente de correlação de Pearson, para identificar o grau de relação entre as variáveis, cujos valores adotados (Tabela 2) para o fator $r$, foram aqueles já utilizados por Porto, Jesus e Pereira Júnior (2017). Posteriormente, utilizou-se o método de Regressão Linear Simples.

\begin{tabular}{|c|c|}
\hline Valores $(r)$ & Descrição \\
\hline 0 & Não há qualquer correlação \\
\hline 0,10 a 0,30 & Correlação fraca \\
\hline 0,40 a 0,60 & Correlação moderada \\
\hline 0,70 a 1,00 & Correlação forte \\
\hline
\end{tabular}

Fonte: Porto, Jesus e Pereira Júnior (2017)

Ambos foram calculados por meio do software Excel 2013. Esse tipo de regressão é utilizado com frequência na análise de dados de séries históricas e é dito linear simples, pois supõe-se linearidade entre as variáveis e por haver uma única variável independente (CARMO, 2016).

A análise de regressão tem como resultado uma equação matemática que descreve o relacionamento entre duas variáveis, uma independente (período dado em anos) e outra dependente (número de habitantes; produção agrícola; número de veículos). Ela pode ser usada para estimar ou predizer, valores futuros ou anteriores de uma variável quando se conhecem ou se supõem conhecidos valores da outra variável (RODRIGUES; MEDEIROS; GOMES, 2013).

Apesar disso, não houve preenchimento das falhas dos três grupos de dados. A produção agrícola possuía série temporal mais extensa (vinte e nove anos) e, portanto, 
mais adequada a uma estimativa próxima à realidade. No entanto, optou-se por não aplicar o método de regressão linear simples a ela, uma vez que diversos fatores a influenciam, dentre eles, as variáveis meteorológicas. Isso torna a análise multivariável, de modo a requerer uma função de estimativa mais complexa (MONTEIRO, 2009; MONTGOMERY; PECY; VINING, 2012).

Da mesma forma, optou-se por não realizar o preenchimento de todas as falhas da série da frota. Os dados referem-se somente a doze anos e o número anual de veículos é baixo. Assim, a estimativa dos vinte e cinco anos anteriores ao primeiro dado seria prejudicada e não se aproximaria da realidade. Contudo, houve preenchimento de dados relativos a dois anos, 2008 e 2017, para completar a série 2005-2017, sem que a análise geral fosse prejudicada. A regressão linear simples foi aplicada por completo apenas na série de população, que se é dada para dezessete anos.

\section{DISCUSSÕES}

\section{CRESCIMENTO URBANO}

Os dados analisados quanto ao crescimento urbano no município de Paragominas - PA foram obtidos por meio de vários indicadores. $\mathrm{O}$ primeiro indicador analisado foi $\mathrm{o}$ crescimento populacional (Tabela 3).

\begin{tabular}{|c|c|}
\hline MOMENTOS & $\begin{array}{l}\text { CRESCIMENTO POPULACIONAL } \\
\text { (habitantes) }\end{array}$ \\
\hline $1965-1979$ & 18.453 \\
\hline $1980-1999$ & 54.780 \\
\hline $2000-2017$ & 94.119 \\
\hline
\end{tabular}

Fonte: autores (2018)

Os dados obtidos indicaram que a taxa de crescimento populacional do primeiro para o segundo período foi maior. Estudo efetuado por Oliveira, Gomes e Cabral (2012), em Paragominas, concluiu que o fluxo migratório, para essa localidade, ocorreu devido tanto à atividade de extração de madeira desenvolvida entre 1980 e 1999, quanto a instrumentos adotados pelo Governo Federal, como a expansão de incentivos fiscais e a reestruturação de órgãos como o Banco da Amazônia, e a Superintendência do Plano de Valorização Econômica da Amazônia. Tais ações foram responsáveis por atrair muitas pessoas de outros municípios e estados.

A análise dos dados obtidos para o crescimento do setor agrícola indicou que, a partir a relação entre Área plantada x área destinada à colheita, mensurada em hectares, houveram períodos distintos de maior e menor crescimento econômico (Figura 2). Porém, constatou-se baixo grau de relação entre as variáveis dependente - área plantada, e independente - período, em anos $(r=0,65309)$. 
Figura 2 - Crescimento do setor agrícola de 1990 a 2016. Paragominas-PA.

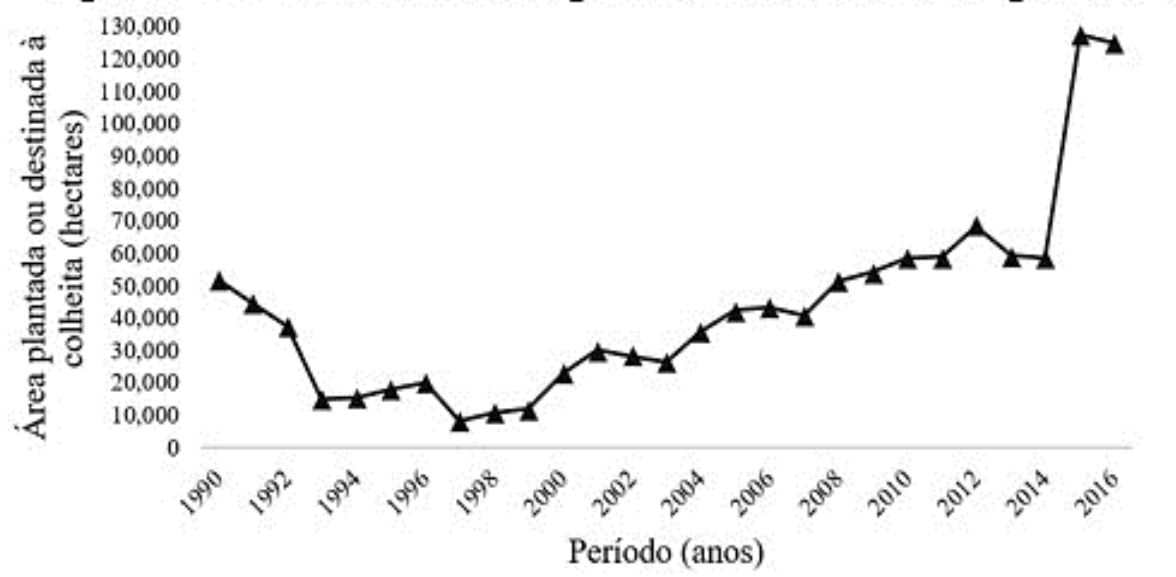

Fonte: autores (2018).

Todavia, os dados obtidos indicaram que houve queda na produção agrícola no início da década de 1990, o que se tornou relativamente estável até 2000. No início do intervalo 2000-2017, pôde-se perceber o crescimento da produção, tendência que foi mantida até o final do período. No Ensaio realizado por Cabral e Gomes (2013), houve indicação da relação entre a transição do uso de terras anteriormente ocupadas com gado para a utilização com a produção de grãos, principalmente a soja ${ }^{1}$ (Glycine max (L) Merrill).

Quando o município passou a investir no setor agrícola em detrimento da extração de madeira, a economia municipal também foi acrescida. Fator que, associado à extração mineral iniciada no município em 2004, contribuiu para o aumento da arrecadação fiscal anual e da circulação interna de capital (BERGAMIN, 2015).

O terceiro e último indicador analisado foi o crescimento da frota de veículos do município (Figura 3).

Figura 3 - Número de veículos da frota municipal de 2005-2017. Paragominas-PA.

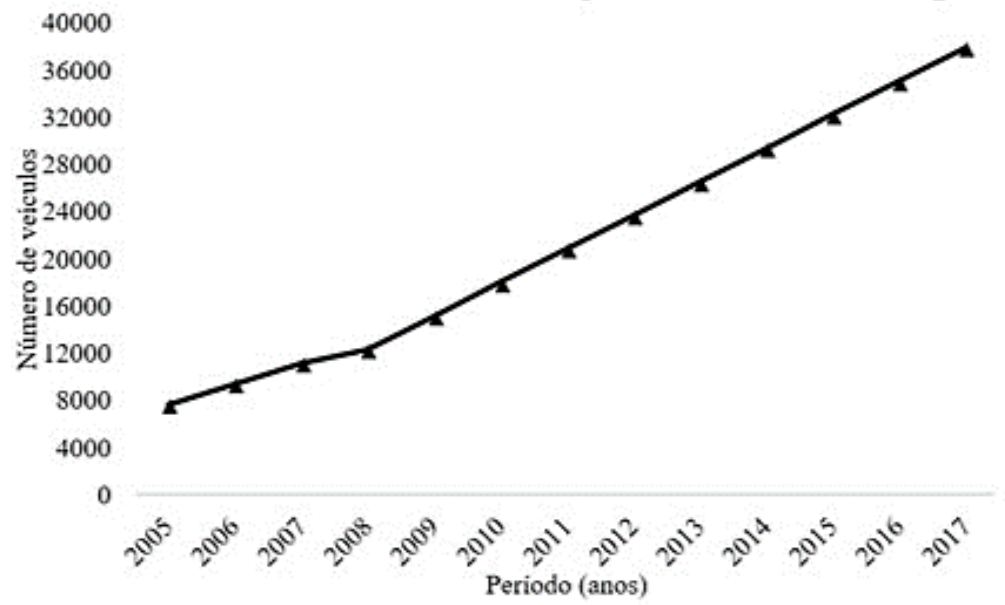

Fonte: autores (2018)

1 Características da soja (NEPOMUCENO; FARIAS; NEUMALER, 2013). Disponível em: <http://www.agencia.cnptia.embrapa.br/gestor/soja/arvore/CONTAG01_24_271020069131.html\#>. 
Os dados obtidos indicam que a frota de veículos cresceu, no período analisado, a uma taxa média equivalente a 2,8. Esse crescimento está atrelado a tendência de elevação na produção agrícola, o que proporcionou o crescimento da economia no mesmo período, pois, há uma correlação $(r=0,8402)$ entre crescimento na primeira e o transporte para o mercado consumidor. Na revisão bibliográfica efetuada por Costa et al. (2013), os autores concluíram que o aumento da frota veicular nos municípios ocorre porque, para desenvolvimento desse tipo de atividade, boas condições de transporte e de infraestrutura são vitais para o crescimento urbano. Essa afirmativa fez-se presente na pesquisa realizada em Paragominas.

\section{IMPACTOS AMBIENTAIS CAUSADOS PELA FROTA VEICULAR EM PARAGOMINAS}

Os padrões de mobilidade urbana são marcados por uma crescente motorização individual e industrial nos diferentes contextos históricos de uma sociedade, o que contribui para a geração de impactos ambientais negativos nos meios biótico, físico e socioeconômico. O primeiro período analisado foi entre 1965 e 1979 (Quadro 2).

\begin{tabular}{|c|c|c|c|}
\hline & & IMPACTOS NEGATTVOS & ORIGEM \\
\hline \multirow{2}{*}{ 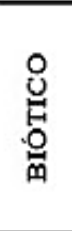 } & DIRETO & $\begin{array}{l}\text { Aumento do risco de atropela- } \\
\text { mento da fauna }\end{array}$ & $\begin{array}{l}\text { O municipio ainda estava pouco desenvol- } \\
\text { vido e com muitas areas verdes na circunvi- } \\
\text { zinhança, o que deixava a fauna vulnerável } \\
\text { ao contato com a população humana }\end{array}$ \\
\hline & INDIRETO & Perda de habitat & $\begin{array}{l}\text { Perda pela interferència humana para cons- } \\
\text { truçào de estradas }\end{array}$ \\
\hline \multirow{4}{*}{ 怘 } & \multirow{3}{*}{ DIRETO } & $\begin{array}{l}\text { Poluição e contaminação do solo } \\
\text { por fuligem, ferros e derivados } \\
\text { de petrolleo, como oleos e graxas }\end{array}$ & $\begin{array}{l}\text { Falta de local adequado para descarte de pe- } \\
\text { ças e utensílios }\end{array}$ \\
\hline & & $\begin{array}{l}\text { Poluição atmosférica por } \mathrm{NO}, \\
\mathrm{CO}_{2}, \mathrm{NO}_{-} \mathrm{SO}_{2} \mathrm{CO} \text { e outros }\end{array}$ & Queima de combustiveis não-renovâieis \\
\hline & & Poluiçẵo sonora & Tráfego de caminhōes boiadeiros \\
\hline & INDIRETO & Desflorestamento & $\begin{array}{l}\text { Retirada da cobertura vegetal para constru- } \\
\text { ção de estradas destinadas ao transporte de } \\
\text { animais e ao acesso da população }\end{array}$ \\
\hline \multirow{2}{*}{ 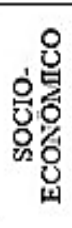 } & DIRETO & Problemas de saúde & $\begin{array}{l}\text { A falta de pavimentação protocava proble- } \\
\text { mas respiratórios. No entanto, nesse peri- } \\
\text { odo, os problemas com poeira não eram tăo } \\
\text { intensos como no periodo de } 1980 \text { a } 1999\end{array}$ \\
\hline & INDIRETO & Acidentes & $\begin{array}{l}\text { Estradas sem pavimento e em más condi- } \\
\text { ções }\end{array}$ \\
\hline
\end{tabular}

Os dados indicaram que o crescimento da frota de veículos movido pelo setor pecuário entre os anos 1965 e 1979 ocasionou diversos impactos, dentre eles, aos aspectos atmosféricos e à possível contaminação do solo. Estudo pioneiro (LEAL, 2000) acerca do cenário socioeconômico do município desde a fundação indica que os transportes ocasionavam problemas de saúde para a população, devido à emissão de poluentes. 
O segundo período de análise de impactos ambientais foi entre 1980 e 1999 (Quadro 3).

Quadro 3 - Identificação dos Impactos ambientais negativos ocorrido no período de 1980 a 1999. Paragominas - PA.

\begin{tabular}{|c|c|c|c|}
\hline & & \\
\hline & & IMPACTOS NEGATIVOS & ORIGEM \\
\hline \multirow{3}{*}{ 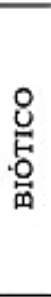 } & \multirow{2}{*}{ DIRETO } & $\begin{array}{l}\text { Aumento do risco de atropelamento } \\
\text { da fauna }\end{array}$ & $\begin{array}{l}\text { O pouco desenvolvido e a grande área verde } \\
\text { próxima ao local de povoamento deixava a fauna } \\
\text { vulnerável ao contato com a população humana }\end{array}$ \\
\hline & & Evasăo da fauna & $\begin{array}{l}\text { O intenso tráfego de veículos pesados durante a } \\
\text { atividade madeireira pode ocasionar o } \\
\text { afugentamento de espécimes }\end{array}$ \\
\hline & INDIRETO & Perda de hábitat & $\begin{array}{c}\begin{array}{c}\text { Perda pela interferência humana para construçăo } \\
\text { de estradas }\end{array} \\
\end{array}$ \\
\hline \multirow{3}{*}{$\stackrel{0}{\circlearrowright}$} & DIRETO & $\begin{array}{l}\text { Contaminação do solo por sucatas, } \\
\text { fuligem, ferros e derivados de } \\
\text { petróleo, como óleos e graxas }\end{array}$ & $\begin{array}{c}\text { Falta de local aplequado para descarte de peças e } \\
\text { utensílios }\end{array}$ \\
\hline & \multirow{2}{*}{ INDIRETO } & $\begin{array}{l}\text { Desvios temporários e permanentes } \\
\text { dos cursos naturais de água }\end{array}$ & $\begin{array}{l}\text { Principalmente devido a construções de estradas } \\
\text { para a atividade madeireira }\end{array}$ \\
\hline & & Desflorestamento & $\begin{array}{l}\text { Abertura de acessos e construções de estradas } \\
\text { para a atividade madeireira }\end{array}$ \\
\hline \multirow{3}{*}{ 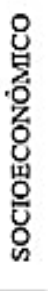 } & DIRETO & Problemas de saúde & $\begin{array}{l}\text { O intenso tráfego de caminhōes madeireiros em } \\
\text { vias não pavimentadas provoca yaproblemas } \\
\text { respiratórios e perda da sensibilidade auditiva }\end{array}$ \\
\hline & \multirow{2}{*}{ INDIRETO } & $\begin{array}{l}\text { Aumento de gastos com } \\
\text { infraestrutura }\end{array}$ & $\begin{array}{c}\text { Manutenção das vias existentes e construção de } \\
\text { novas }\end{array}$ \\
\hline & & $\begin{array}{l}\text { Possiveis danos à saúde } \\
\text { pública }\end{array}$ & $\begin{array}{l}\text { Descarte inadequado de pneus que pode } \\
\text { beneficiar a disseminação de vetores e doenças. }\end{array}$ \\
\hline
\end{tabular}

Fonte: autores (2018).

Quanto aos transportes, durante o auge da extração madeireira, eles foram responsáveis por causar impactos negativos relacionados principalmente à saúde da população como: problemas respiratórios e perda da sensibilidade auditiva, e ao desflorestamento, que além de ser a atividade econômica principal também requer derrubadas para aberturas de acessos e construção de estradas, esses e outros aspectos são observados na tabela abaixo (OLIVEIRA et al., 2010).

Por fim, o terceiro período de análise de impactos ambientais relacionado à frota veicular foi entre 2000 e 2017 (Quadro 4). 
Quadro 4 - Impactos ambientais negativos no período de 2000 a 2017. Paragominas-

PA.

\begin{tabular}{|c|c|c|c|}
\hline & & IMPACIOS NEGATIVOS & ORIGEM \\
\hline \multirow{2}{*}{ 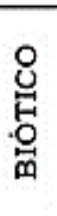 } & DIRETO & Atropelamento de fauna & $\begin{array}{l}\text { Apesar de a cidade já estar urbanizada, há } \\
\text { areas verde próximas à zona urbana, de onde } \\
\text { podem sair animais em direção às estradas }\end{array}$ \\
\hline & INDIRETO & Contaminação da fauna e da flora & $\begin{array}{c}\text { Falta de destinação adequada de ôleos e gra- } \\
\text { xas }\end{array}$ \\
\hline \multirow{5}{*}{ 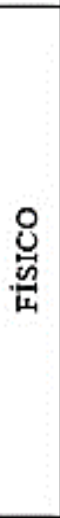 } & \multirow{3}{*}{ DIRETO } & $\begin{array}{c}\text { Consumo/ocupação de recursos } \\
\text { naturais (solo) }\end{array}$ & $\begin{array}{l}\text { O crescimento da frota municipal requer cada } \\
\text { rez mais espaço para circulaçăo e estaciona- } \\
\text { mento. }\end{array}$ \\
\hline & & $\begin{array}{l}\text { Contaminaçăo do solo por suca- } \\
\text { tas, fuligem, ferros e derivados } \\
\text { de petróleo, como óleos e graxas }\end{array}$ & $\begin{array}{l}\text { Falta de local adequado para descarte de pe- } \\
\text { ças e utensilios }\end{array}$ \\
\hline & & Polvição atmosfërica & $\begin{array}{l}\text { Aumento da emissão de gases poluentes de- } \\
\text { vido ao crescimento do número de veiculos }\end{array}$ \\
\hline & \multirow[t]{2}{*}{ INDIRETO } & Aumento da temperatura local & $\begin{array}{l}\text { Devido ao aumento da emissão de gases polu- } \\
\text { entes provocado pelo crescimento do número } \\
\text { de veiculos e de vias pavimentadas }\end{array}$ \\
\hline & & $\begin{array}{l}\text { Redução dos niveis de infilttração } \\
\text { e percolação nas vias públicas }\end{array}$ & $\begin{array}{l}\text { Impermeabilizaçąo das vias públicas por as- } \\
\text { faltamento }\end{array}$ \\
\hline \multirow{4}{*}{ 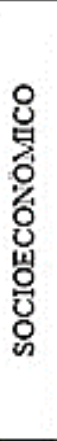 } & \multirow[b]{2}{*}{ DIRETO } & Aumento do número de acidentes & $\begin{array}{l}\text { Devido à maior circulação de veiculos, o que } \\
\text { também provoca a degradaçăo das vias e pro- } \\
\text { picia ainda mais a ocorrência de acidentes }\end{array}$ \\
\hline & & Congestionamento & $\begin{array}{l}\text { Interfere nas relaçŏes sociais e é ocasionado } \\
\text { pelo grande número de veiculos em determi- } \\
\text { nado local, principalmente nos horários de } \\
\text { pico }\end{array}$ \\
\hline & \multirow{2}{*}{ INDIRETO } & $\begin{array}{l}\text { Aumento dos gastos com infraes- } \\
\text { trutura de transportes }\end{array}$ & $\begin{array}{l}\text { Melhoria da infraestrutura para que a frota } \\
\text { circule com seguranca e conforto }\end{array}$ \\
\hline & & Possíveis danos à saúde pública & $\begin{array}{l}\text { Descarte inadequado de pneus que pode bene- } \\
\text { ficiar a disseminação de vetores e doenças. }\end{array}$ \\
\hline
\end{tabular}

Fonte: autores (2018).

Os dados indicaram que, a partir de 2000, o município de Paragominas-PA passou por uma transição econômica voltada para o setor da mineração e agricultura, o que intensificou, juntamente à urbanização, os impactos causados pelo setor de transportes. Na revisão bibliográfica realizada por Castro (2013), sobre as externalidades ocorridas no transporte de carga, esse autor concluiu que a expansão da frota municipal de veículos ocasionou impactos relacionados, principalmente, à poluição, à ocupação do solo ao congestionamento, e a acidentes, o que é resultado da transição e novas formas de atividade desenvolvidas.

\section{CONSIDERAÇÕES FINAIS}

A análise quantitativa do crescimento urbano de Paragominas-PA evidenciou o aumento da população, da produção agrícola e, consequentemente, da frota municipal, devido às atividades econômicas realizadas desde a fundação do município, em 1965. 
Esse crescimento, no entanto, não ocorreu em conjunto com a observação dos aspectos ambientais locais.

Os dados qualitativos de identificação de impactos ambientais indicaram que a preocupação do município, no segundo período analisado, com questões essencialmente socioeconômicas, em detrimento daquelas ambientais, foi responsável por ocasionar diversos impactos ambientais negativos. Verificou-se que as listagens de impactos foram mais preenchidas para os dois últimos períodos, quando houve, respectivamente, trânsito intenso de caminhões madeireiros e meio crescimento do número de veículos e de vias pavimentadas.

\section{REFERENCIAS}

ALMEIDA, M. R. R.; MONTAÑO, M. Benchmarking na avaliação de impacto ambiental: o sistema mineiro frente às melhores práticas internacionais. Soc. \& Nat, Uberlândia, v. 27, n. 1, p.81-96, jan. /abr. 2015.

BASTOS, T. X. et al. Informações agroclimáticas do município de Paragominas para o planejamento agrícola. 2010. Disponível em: <https://ainfo.cnptia.embrapa.br/digital/

BATTERMAN, S.; CHAMBLISS, S.; ISAKOV, V. Spatial resolution requirements for traffic-related air pollutant exposure evaluations. Atmospheric Environment, v. 94, p.518-528, set. 2014.

BERGAMIN, M. S. Paragominas: a experiência para se tornar um município verde na Amazônia. Belém: Marques Editora, 2015.

BRASIL. Conselho Nacional do Meio Ambiente. Resolução n. 001, de 23 de janeiro de 1986. Dispõe sobre critérios básicos e diretrizes gerais para a avaliação de impacto ambiental. Diário Oficial [da] República Federativa do Brasil, Poder Executivo, Brasília, DF, de 17 fev. 1986, p. 2548-2549.

CABRAL, E. R.; GOMES, S. C. Gestão ambiental pública em municípios com forte correlação entre desmatamento e expansão da pecuária, da soja e da madeira. Ensaios FEE, Porto Alegre, v. 34, n. 1, p. 167-194, jul. 2013.

CARMO, C. R. S. Análise de regressão linear e atualização monetária de valores: um estudo considerando modelagens preditivas de custos com componentes fixos e variáveis. RAGC. Monte Carmelo, v. 4, n. 9, p. 44-56, 2016.

CASTRO, N. Mensuração de externalidades do transporte de carga brasileiro. Journal of Transport Literature. Manaus, v. 7, n. 1, p. 163-181, jan. 2013.

COSTA, C. C. M. et al. Determinantes do desenvolvimento do setor agropecuário nos municípios. Revista de Administração. São Paulo, v. 48, n. 2, p. 295-309, abr./jun. 2013. 
CREMONEZ, F. E. et al. Avaliação de impacto ambiental: metodologias aplicadas no Brasil. Revista Monografias Ambientais. Santa Maria, v. 13, n. 5, p. 3821-3830, dez. 2014.

IBGE. INSTITUTO BRASILEIRO DE GEOGRAFIA E ESTATÍSTICA. Cidades. 2010, 2016, 2017. Disponível em: <https://cidades.ibge.gov.br/brasil/pa/paragominas/panorama>. Acesso em 17 mar. 2018.

LEAL, G. L. R. Paragominas: A realidade do pioneirismo. 2 ed. Belém: Alves, 2000.

MACHADO, L. M. V.; LOBO, M. A. A.; TOURINHO, H. L. Z. Dispersão e fragmentação urbana em cidades intermediárias: o caso de Paragominas (PA). ACTA Geográfica, Boa Vista, v. 9, n. 20, p. 1-15, set. /dez. 2015.

MIRAGLIA, S. G. E. K.; GOUVEIA, N. Custos da poluição atmosférica nas regiões metropolitanas brasileiras. Ciência \& Saúde Coletiva. Rio de Janeiro, v. 2, n. 3, p. 41414147, 2014.

MONTEIRO, J. E. B. A. Agrometeorologia dos cultivos: O fator meteorológico na produção agrícola. Brasília: INMET, 2009.

MONTGOMERY, D. C.; PECK, E. A.; VINING, G. G. Introduction to Linear Regression Analysis. 5 ed. New Jersey: Wiley, 2012.

OLIVEIRA, F. C.; MOURA, H. J. T. Uso das metodologias de avaliação de impacto ambiental em estudos realizados no Ceará. Pretexto, Belo Horizonte, v. 10, n. 4, p. 7998, out. /dez. 2009.

OLIVEIRA, R. S.; GOMES, S. C.; CABRAL, E. R. Da condição de município "Marrom" a município "Verde": o caso de Paragominas - PA. Revista de Administração e Negócios da Amazônia, Rondônia, v. 4, n. 2, p. 122-139, 2012.

PARIZOTTO, R. et al. Identificação e classificação dos aspectos e dos impactos ambientais em uma empresa metal mecânica. In: CONGRESSO INTERNACIONAL DE TECNOLOGIAS PARA O MEIO AMBIENTE, 3. 2012, Bento Gonçalves. Anais... Bento Gonçalves: A Mc-graw-hill Ltda, 2012. p. 201-210.

PINTO, A. et al. Diagnóstico Socioeconômico e Florestal do município de Paragominas. Relatório Técnico. Belém: Instituto do Homem e Meio Ambiente da Amazônia - $\quad$ Imazon. $2009 . \quad$ Disponível em: $<$ http://imazon.org.br/PDFimazon/Portugues/outros/iagnostico-socioeconomico-eflorestal-do.pdf>. Acesso em: 17 mar. 2018.

PORTO, M. L.; JESUS, E. S.; PEREIRA JÚNIOR, A. Análise das tendências nas relações entre o fluxo de veículos, arborização e os níveis de intensidade de ruído. Ecologia e Nutrição Florestal. Santa Maria, v. 5, n. 3, p. 87 - 97, set. /dez. 2017. 
PRODANOV, C. C.; FREITAS, E. C. Metodologia do Trabalho Científico: Métodos e Técnicas da Pesquisa e do Trabalho Acadêmico. 2 ed. Novo Hamburgo: Feevale, 2013.

RODRIGUES, R. L.; MEDEIROS, F. P. A.; GOMES, A. S. Modelo de Regressão Linear aplicado à previsão de desempenho de estudantes em ambiente de aprendizagem. In: CONGRESSO BRASILEIRO DE INFORMÁTICA NA EDUCAÇÃOO, 2. 2013, São Paulo. Anais... Limeira: Unicamp, 2013.

SAKAMOTO, C. K.; SILVEIRA, I. O. Como fazer projetos e Iniciação Científica. São Paulo: Paulus, 2014.

TURRA, A. et al. Avaliação de impacto ambiental sob uma abordagem ecossistêmica: ampliação do porto de São Sebastião. Ambiente \& Sociedade, São Paulo, v. 20, n. 3, p.160-180, jul. /set. 2017.

XIMENES, A. R. et al. O impacto ambiental devido à política de crescimento da frota de veículos. Revista Ciências do Ambiente On-line, v. 4, n. 2, ago. 2008. Disponível em: <http://sistemas.ib.unicamp.br/be310/nova/index.php/be310/article/viewFile/157/113>. Acesso em 18 mar. 2018. 